\title{
Obstructive sleep apnea syndrome and hypertension: ambulatory blood pressure
}

\author{
Kazuomi Kario
}

Obstructive sleep apnea syndrome (OSAS) is an independent risk factor for hypertension and cardiovascular disease. OSAS is the frequent underlying disease of secondary hypertension and resistant hypertension. OSAS increases both daytime and night-time ambulatory blood pressures through the activation of various neurohumoral factors including the sympathetic nervous system and the renin-angiotensin-aldosterone system. In particular, OSAS predominantly increases ambulatory BP during sleep compared with the awake period, with the result that OSAS is likely to be associated with the non-dipping pattern (diminished nocturnal BP fall) or riser pattern (higher sleep BP than awake BP) of nocturnal BP. An additional characteristic of ABP in OSAS is increased BP variability. The newly developed non-invasive hypoxia-trigger BP-monitoring system detected marked midnight BP surges (ranging from around 10 to $100 \mathrm{~mm} \mathrm{Hg}$ ) during sleep in OSAS patients. The exaggerated BP surge may trigger OSAS-related cardiovascular events occurring during sleep. Clinically, as nocturnal hypoxia is the determinant of morning minus evening BP difference (ME difference), OSAS should be strongly suspected when morning BP cannot be controlled $<135 / 85 \mathrm{~mm} \mathrm{Hg}$ with increased ME difference even by the specific antihypertensive medications targeting morning hypertension such as bedtime dosing of antihypertensive drugs. Understanding the characteristics of OSAS-related hypertension is essentially important to achieve perfect BP control over a 24-h period, including the sleep period, for more effective prevention of cardiovascular disease.

Hypertension Research (2009) 32, 428-432; doi:10.1038/hr.2009.56

Keywords: ambulatory blood pressure non-dippers; midnight surge in blood pressure; risers; sleep apnea syndrome

\section{INTRODUCTION}

Obstructive sleep apnea syndrome (OSAS), one of the leading causes of hypertension, is a risk for advancing atherosclerosis and for triggering cardiovascular events, particularly those occurring during the sleep period. In the recently published guidelines for the management of hypertension, more strict blood pressure (BP) control during a 24-h period is particularly stressed for high-risk hypertensive patients. ${ }^{1,2}$ Hypertensive patients with OSAS constitute one of the high-risk groups that receive more benefit from strict BP control. Thus, understanding the characteristics of OSAS-related hypertension is essentially important to achieve perfect BP control over a 24-h period, including the sleep period, for more effective prevention of cardiovascular disease.

\section{CAUSE OF HYPERTENSION}

OSAS is the most common identifiable cause of secondary hypertension that could be recognized as a high-risk metabolic syndrome. Being male and obese are the two major risk factors for OSAS; however, the prevalence of OSAS has not been shown in Japan.

OSAS and hypertension are likely to accompany each other; the prevalence of OSAS has been underscored in hypertensive patients. ${ }^{3}$
Fifty percent or more of all OSAS patients have hypertension and around $30 \%$ of all obese hypertensive patients in Western countries may have OSAS. The higher rates of coexistence of hypertension and OSAS are due to the increased prevalence of obesity, a background factor in both conditions.

However, the precise prevalence of OSAS in hypertensive patients has not been identified in Japan. We have previously studied the prevalence of SAS diagnosed using the same polysomnography device and the same criteria (15 > apnea hypopnea index (AHI)) as that of the Sleep Heart Health Study (SHHS) in 452 Japanese hypertensive patients. ${ }^{4}$ The prevalence of OSAS in Japanese hypertensives was around 10\%, and this value was one-third that of the Western hypertensive participants of the New York SHHS (Figure 1). OSAS increases with obesity in Japan, but is also frequently observed in non-obese individuals with particular skeletal characteristics of the face such as micrognathia. ${ }^{5}$

The association between OSAS and hypertension is found before both conditions become clinically overt. In the population-based Wisconsin Sleep Cohort Study, an increase in AHI was a predictor of future hypertension independently of age and body mass index. ${ }^{6}$ In addition, there is an independent linear association between AHI and 24-h BP levels. ${ }^{7}$ 
Prevalence of Sleep Apnea Syndrome in Hypertension

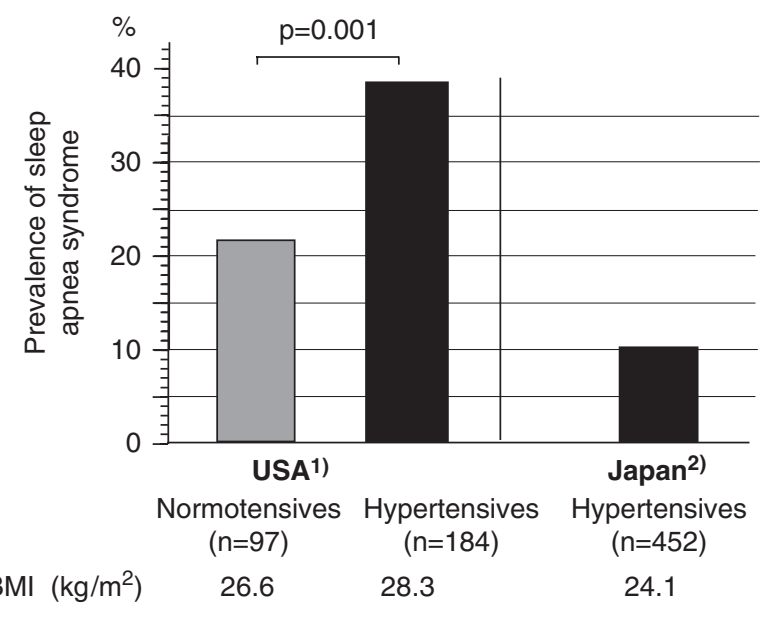

Figure 1 Prevalence of sleep apnea syndrome in hypertension. ${ }^{1)}$ New York Sleep Heart Health Study; ${ }^{2}$ Jichi Medical University Ambulatory BP Monitoring Study Wave 2 Core; BMI, body mass index.

The impact of OSAS on hypertension is higher for diastolic hypertension in younger individuals than for systolic hypertension in the elderly. ${ }^{8}$ Sleep is important for increased BP in younger individuals. A recent study evaluated the quantity and quality of sleep using actigraphy in adolescence individuals; short sleep duration $(<6.5 \mathrm{~h})$ and decreased sleep efficacy $(<85 \%)$ were independent risk factors for prehypertension. ${ }^{9}$

In the population-based Jichi Medical School Cohort, ${ }^{10}$ as well as the Suita Study, ${ }^{11}$ prehypertension is a risk factor for cardiovascular disease, particularly stroke, in Japan. The strong and independent determinant of prehypertension was obesity, particularly in younger subjects aged $<50$ years. ${ }^{12}$ In the community-dwelling subjects (aged 45 years), a $10 \%$ increase in body mass index over 4 years increased the risk of moderate to severe OSAS sixfold, and the risk was suppressed by body weight reduction. ${ }^{13}$ Thus, adequate control of body weight is essential for the prevention of OSAS-related hypertension from a young age.

\section{RESISTANT HYPERTENSION}

OSAS is known to be a frequent cause of resistant hypertension (Table 1). ${ }^{14}$ Resistant hypertension is defined when BP levels cannot be controlled $<140 / 90 \mathrm{~mm} \mathrm{Hg}$ by the use of three drugs, including diuretics. ${ }^{1}$ Some reports have shown that the prevalence of OSAS (defined as $\mathrm{AHI}>10$ ) is $80 \%$ or more, ${ }^{15}$ and that OSAS is the independent determinant of uncontrolled hypertension in younger hypertensive patients aged $<50$ years. ${ }^{16}$ An increased level of plasma aldosterone is reported to be associated with resistant hypertension in OSAS patients. ${ }^{17}$

\section{MASKED HYPERTENSION}

The most important characteristic of OSAS-related hypertension is the higher frequency of masked hypertension such as nocturnal hypertension and morning hypertension (Table 1).

Masked hypertension is defined as an average clinic BP of $<140 / 90 \mathrm{~mm} \mathrm{Hg}$ and home BP of $\geqslant 135 / 85 \mathrm{~mm} \mathrm{Hg}$ or an average 24-h BP on ambulatory BP monitoring of $\geqslant 130 / 80 \mathrm{~mm} \mathrm{Hg}$. ${ }^{1,2,18,19}$ Masked hypertension includes morning hypertension, stress-induced hypertension, such as workplace hypertension, ${ }^{1}$ and nocturnal hypertension. Nocturnal hypertension is defined as a sleeping BP
Table 1 Characteristics of hypertension with obstructive sleep apnea syndrome

Resistant hypertension

Masked hypertension

Nocturnal hypertension (non-dipper-riser pattern, midnight BP surge)

Morning hypertension (exaggerated morning BP surge)

Hypertension with increased heart rate

Diastolic (predominant) hypertension in younger

Abbreviation: $\mathrm{BP}=$ blood pressure.

of $>120 / 70 \mathrm{~mm} \mathrm{Hg}$, and morning hypertension is defined as a morning BP of $>135 / 85 \mathrm{~mm} \mathrm{Hg} .{ }^{1}$ OSAS increases the awake BP during the daytime, but more extensively it increases nocturnal BP during the sleep period. Thus, OSAS patients are likely to have a nondipper/riser pattern of nocturnal BP. This nocturnal hypertension (non-dipper/riser pattern) could be detected as morning hypertension by self-measured home BP monitoring (Figure 2). ${ }^{20}$

It is important to suspect OSAS when morning hypertension (assessed using self-measured BP monitoring) cannot be controlled $<135 / 85 \mathrm{~mm} \mathrm{Hg}$ even by the specific antihypertensive treatment targeting morning hypertension using bedtime administration of antihypertensive drugs. In addition, the increased difference between morning and evening BP (ME-BP difference) detected by self-measured home BP monitoring may suggest the presence of OSAS in uncontrolled hypertension. Nocturnal hypoxia is one of the determinants of increased ME-BP difference in BP, and an increase in ME-BP difference is associated with hypertensive heart disease, particularly concentric left ventricular hypertrophy and future stroke events in hypertensive patients independently of the average of morning and evening BPs. ${ }^{21,22}$

\section{NON-DIPPER/RISER IN NOCTURNAL BLOOD PRESSURE}

Non-dippers (reduced nocturnal BP fall) and risers (higher nocturnal $\mathrm{BP}$ than daytime BP) are at risk of hypertensive target organ damage and subsequent cardiovascular events. ${ }^{23-29}$ The related conditions of non-dippers and risers are as follows: (1) reduced circulating volume (congestive heart failure, chronic kidney disease, etc), (2) autonomic nervous dysfunction (orthostatic hypotension, diabetes, etc) and (3) poor sleep quality (SAS, depression, etc) (Figure 2). ${ }^{30}$ The prevalence of OSAS is higher in these conditions, such as congestive heart failure, chronic kidney disease, diabetes, and so on, and may partly contribute to increased nocturnal hypertension.

\section{MIDNIGHT SURGE IN SLEEP BLOOD PRESSURE}

Another important characteristic of OSAS-related nocturnal hypertension accompanies the increased BP variability during sleep. In OSAS patients, an invasive BP monitoring showed transient BP surges because of sympathetic activation at the time of the sleep apnea episode. A continuous non-invasive BP monitoring, such as Finapress, could also detect the transient BP surge; however, the absolute BP value is inaccurate. We have recently developed a new home BPmonitoring system in which reduction of $\mathrm{O}_{2}$ desaturation owing to each apnea episode triggers a cuff-inflation system to accurately measure the sleep apnea-associated BP variation during sleep. ${ }^{31}$ Using this new system, we have monitored BP during sleep in OSAS patients and found that there are marked individual differences (from 10 to $100 \mathrm{~mm} \mathrm{Hg}$ ) in the degree of midnight BP surges triggered by a similar degree of desaturation at the time of the sleep apnea episode. Figure 3 shows a case that exhibited marked midnight BP 


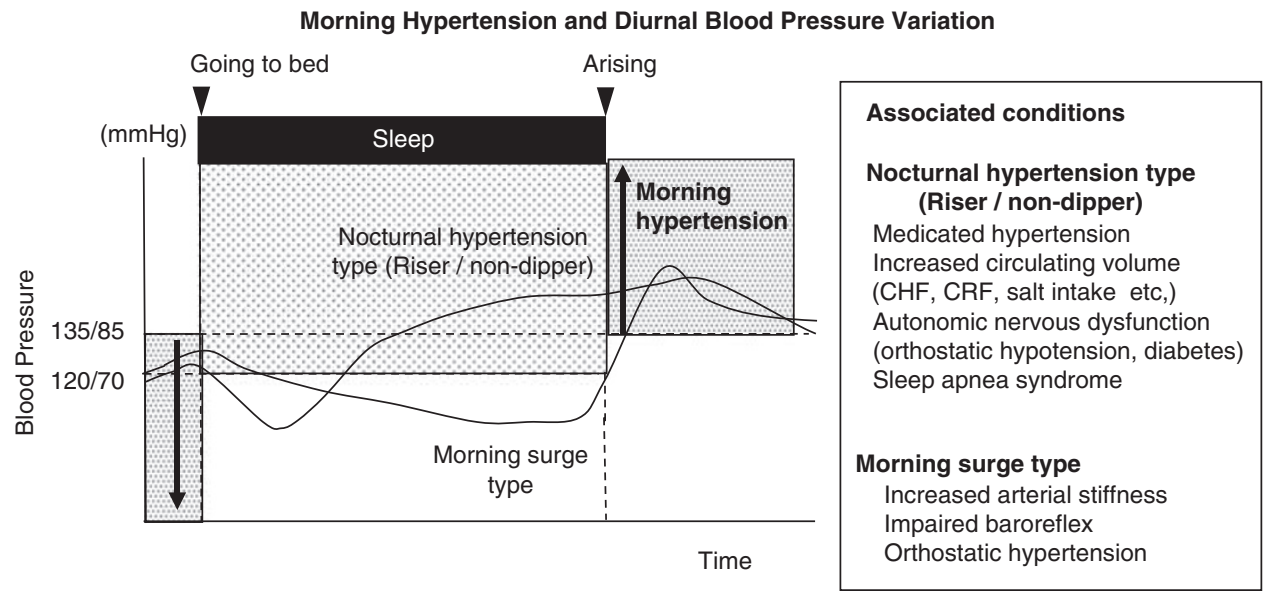

Figure 2 Morning hypertension and diurnal blood pressure variation. CHF, congestive heart failure; CRF, chronic renal failure.

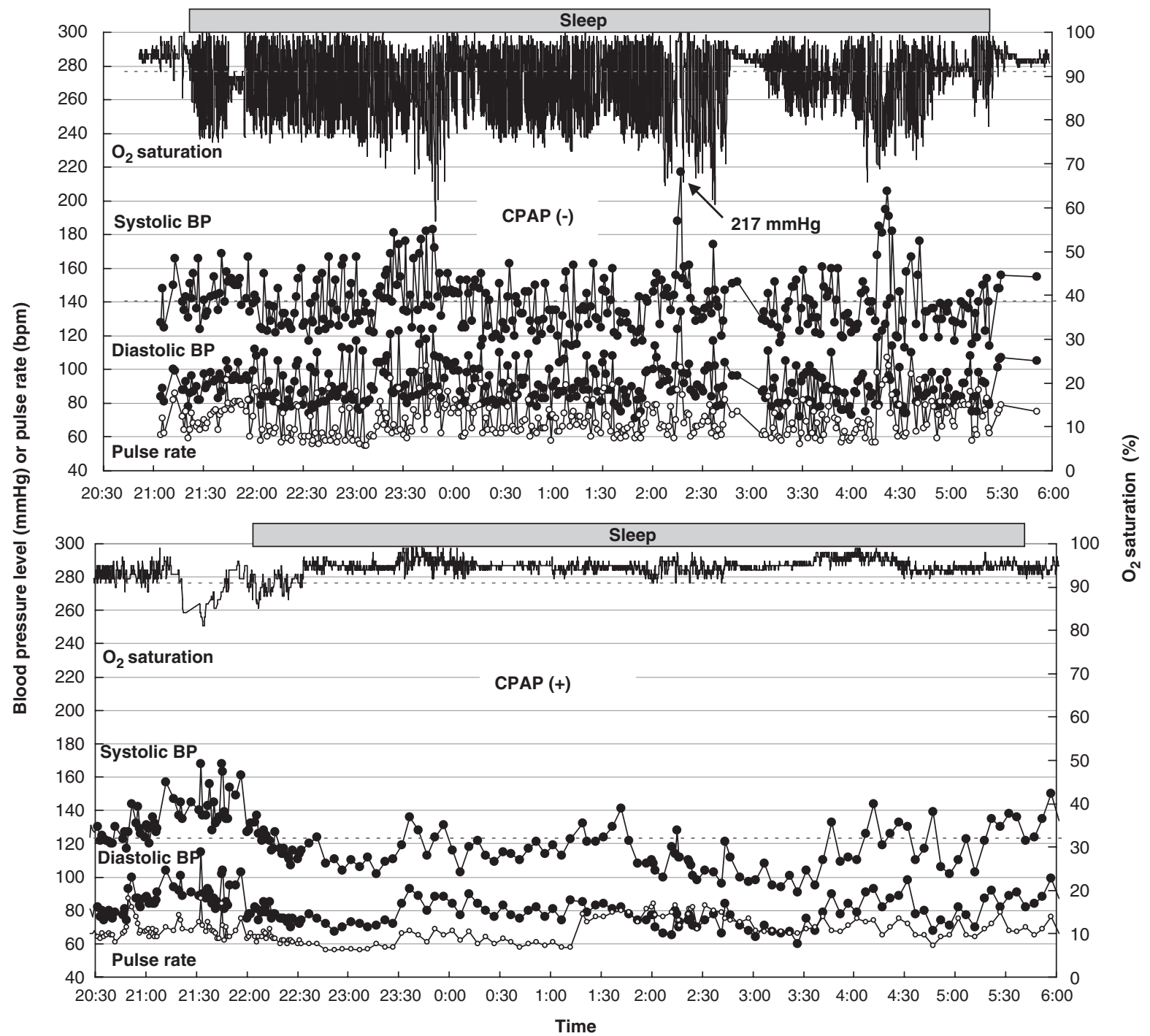

Figure 3 Sleep apnea-related midnight BP surges detected by newly developed hypoxia-trigger BP-monitoring system. (Upper figure) Using this system, we monitored the sleeping BP in a 54-year-old male patient (body mass index: $33.1 \mathrm{~kg} \mathrm{~m}^{-2}$ ) with severe obstructive sleep apnea. BP variation during sleep as actually augmented (s.d. of sleeping BPs $=16.6 \mathrm{~mm} \mathrm{Hg}$ ), with several high BP peaks ( $3.4 \%$ of the total systolic BPs measured during sleep were above $180 \mathrm{~mm} \mathrm{Hg}$ ). (Lower figure) During continuous positive airway pressure (CPAP), in addition to the reduction of average BPs $(-18.6 \mathrm{~mm} \mathrm{Hg}$ systolic and $-11.4 \mathrm{~mm} \mathrm{Hg}$ diastolic), BP variation also decreased with reduced peak BPs. 


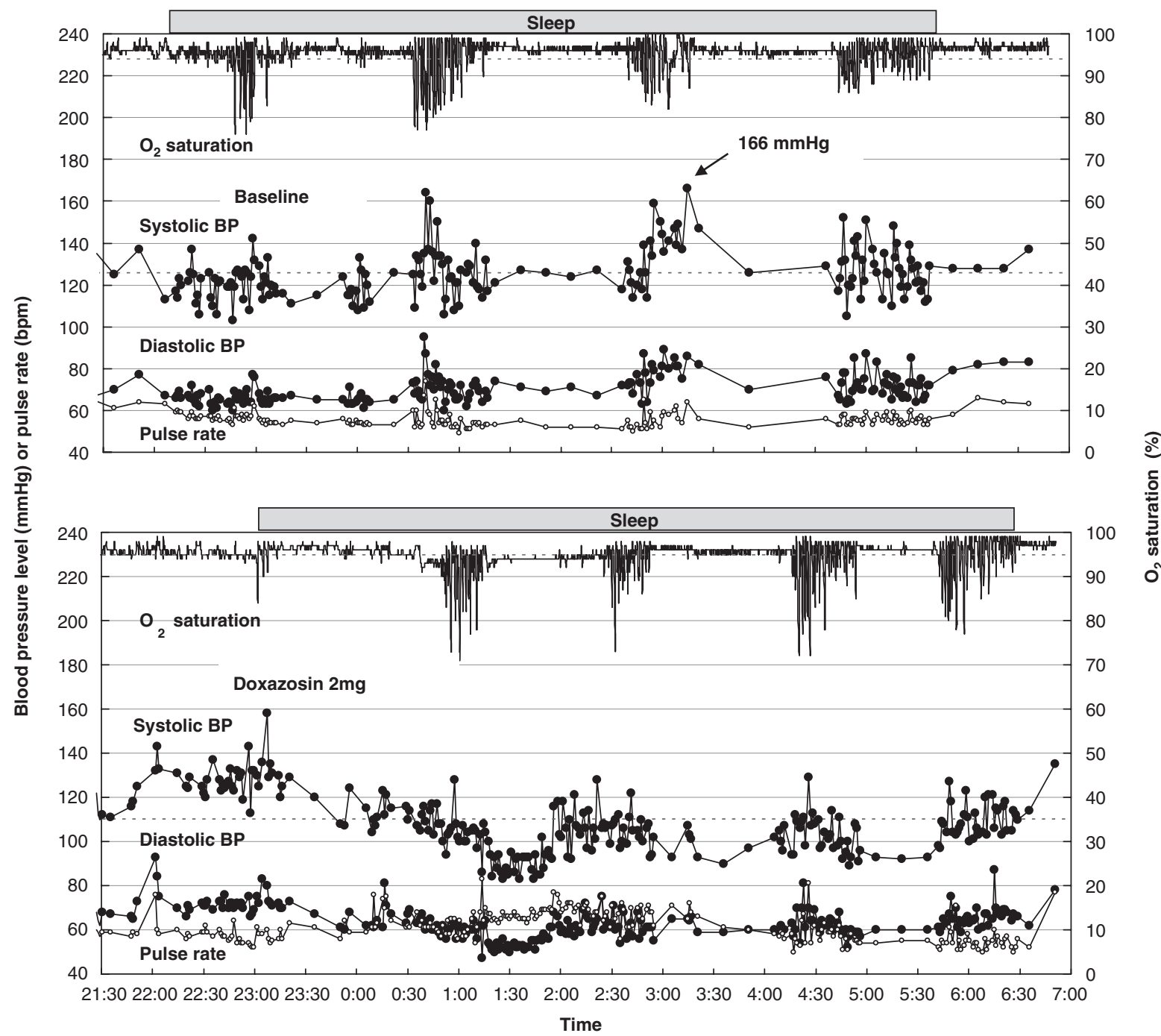

Figure 4 Reduction of sleep apnea-related midnight BP surges by $\alpha$-adrenergic blockade. (Upper figure) Periodic clusters of sleep apnea episodes triggered midnight BP surges $>160 \mathrm{~mm} \mathrm{Hg}$. (Lower figure) Bedtime dosing of doxazosin $(2 \mathrm{mg}$ ) did not reduce the periodic hypoxic episodes, but diminished nocturnal $\mathrm{BP}$ levels and midnight BP surges $<140 \mathrm{~mm} \mathrm{Hg}$.

surges triggered by sleep apnea episodes. These BP surges were significantly diminished by continuous positive airway pressure therapy. The increased midnight $\mathrm{BP}$ surge may be a missing direct link between OSAS and cardiovascular events occurring particularly during sleep.

The individual difference and pathogenesis of midnight BP surges remain unclear. A bedtime dosing of $\alpha$-adrenergic blockade diminished this BP surge (Figure 4), indicating that midnight BP surge is predominantly triggered by sympathetic nervous activation and subsequent vasoconstriction. In OSAS patients, BP reactivity to sympathetic activation may be increased. Even in children without any atherosclerosis, morning BP surge is exaggerated in severe OSAS patients compared with non-OSAS subjects. ${ }^{32}$

\section{CONCLUSION}

Hypertensive patients with OSAS constitute a high-risk group, and the characteristic of ambulatory BP in OSAS patients is uncontrolled nocturnal/morning hypertension with midnight BP surge. Strict BP control to lower the target level with particular attention to nocturnal
BP is required to prevent target organ damage and cardiovascular events occurring particularly during sleep.

\section{CONFLICT OF INTEREST}

The authors declare no conflict of interest.

1 Ogihara T, Kikuchi K, Matsuoka H, Fujita T, Higaki J, Horiuchi M, Imai Y, Imaizumi T, Ito S, Iwao H, Kario K, Kawano Y, Kim-Mitsuyama S, Kimura G, Matsubara H, Matsuura H, Naruse M, Saito I, Shimada K, Shimamoto K, Suzuki H, Takishita S, Takahashi N, Tsuchihasi T, Uchiyama M, Ueda S, Ueschima H, Umemura S, Ishimitsu T, Rakugi H. The Japanese Society of Hypertension Committee for Guideline for the Management for Hypertension. Hypertens Res 2009; 32: 3-107.

2 Mancia G, De Backer G, Dominiczak A, Cifkova R, Fagard R, Germano G, Grassi G, Heagerty AM, Kjeldsen SE, Laurent S, Narkiewicz K, Ruilope L, Rynkiewicz A, Schmieder RE, Boudier HA, Zanchetti A, Vahanian A, Camm J, De Caterina R, Dean V, Dickstein K, Filippatos G, Funck-Brentano C, Hellemans I, Kristensen SD, McGregor K, Sechtem U, Silber S, Tendera M, Widimsky P, Zamorano JL, Erdine S, Kiowski W, Agabiti-Rosei E, Ambrosioni E, Lindholm LH, Viigimaa M, Adamopoulos S, AgabitiRosei E, Ambrosioni E, Bertomeu V, Clement D, Erdine S, Farsang C, Gaita D, Lip G, Mallion JM, Manolis AJ, Nilsson PM, O'Brien E, Ponikowski P, Redon J, Ruschitzka F, 
Tamargo J, van Zwieten P, Waeber B, Williams B. Management of Arterial Hypertension of the European Society of Hypertension; European Society of Cardiology. J Hypertens 2007; 25: 1105-1187.

3 Somers VK, White DP, Amin R, Abraham WT, Costa F, Culebras A, Daniels S, Floras JS, Hunt CE, Olson LJ, Pickering TG, Russell R, Woo M, Young T, American Heart Association Council for High Blood Pressure Research Professional Education Committee, Council on Clinical Cardiology; American Heart Association Stroke Council; American Heart Association Council on Cardiovascular Nursing; American College of Cardiology Foundation. Sleep apnea and cardiovascular disease: an American Heart Association/american College Of Cardiology Foundation Scientific Statement from the American Heart Association Council for High Blood Pressure Research Professional Education Committee, Council on Clinical Cardiology, Stroke Council, and Council On Cardiovascular Nursing. In collaboration with the National Heart, Lung, and Blood Institute National Center on Sleep Disorders Research (National Institutes of Health). Circulation 2008; 118: 1080-1111. e-pub 25 August 2008.

4 Kario K, Ishikawa J, Hoshide S, Ishikawa S, Eguchi K, Pickering TG, Shimada K. Vascular Consequences of Sleep Disordered Breathing-Sleep apnea syndrome and hypertensive target organ damage in Japan. The American Society of Hypertension 21st Annual Scientific Meeting and Exposition, New York, May 16-20, 2006.

5 Endo S, Mataki S, Kurosaki N. Cephalometric evaluation of craniofacial and upper airway structures in Japanese patients with obstructive sleep apnea. J Med Dent Sci 2003; 50: 109-120.

6 Peppard PE, Young T, Palta M, Skatrud J. Prospective study of the association between sleep-disordered breathing and hypertension. N Engl J Med 2000; 342: 1378-1384.

7 Young T, Peppard P, Palta M, Hla KM, Finn L, Morgan B, Skatrud J. Population-based study of sleep-disordered breathing as a risk factor for hypertension. Arch Intern Med 1997; 157: 1746-1752.

8 Haas DC, Foster GL, Nieto FJ, Redline S, Resnick HE, Robbins JA, Young T, Pickering TG. Age-dependent associations between sleep-disordered breathing and hypertension: importance of discriminating between systolic/diastolic hypertension and isolated systolic hypertension in the Sleep Heart Health Study. Circulation 2005; 111: 614-621.

9 Javaheri S, Storfer-Isser A, Rosen CL, Redline S. Sleep quality and elevated blood pressure in adolescents. Circulation 2008; 118: 1034-1040.

10 Ishikawa S, Kario K, Kayaba K, Gotoh T, Nago N, Nakamura Y, Tsutsumi A, Kajii E, Jichi Medical School (JMS) Cohort Study Group. Linear relationship between blood pressure and stroke: the Jichi Medical School Cohort Study. J Clin Hypertens 2007; 9: 677-683.

11 Kokubo Y, Kamide K, Okamura T, Watanabe M, Higashiyama A, Kawanishi K, Okayama A, Kawano Y. Impact of high-normal blood pressure on the risk of cardiovascular disease in a Japanese urban cohort: the Suita study. Hypertension 2008; 52: $652-659$.

12 Ishikawa Y, Ishikawa J, Ishikawa S, Kayaba K, Nakamura Y, Shimada K, Kajii E, Pickering TG, Kario K, Jichi Medical School Cohort Investigators Group. Prevalence and determinants of prehypertension in a Japanese general population: the Jichi Medical School Cohort Study. Hypertens Res 2008; 31: 1323-1330.

13 Peppard PE, Young T, Palta M, Dempsey J, Skatrud J. Longitudinal study of moderate weight change and sleep-disordered breathing. JAMA 2000; 284: 3015-3021.

14 Calhoun DA, Jones D, Textor S, Goff DC, Murphy TP, Toto RD, White A, Cushman WC, White W, Sica D, Ferdinand K, Giles TD, Falkner B, Carey RM, American Heart Association Professional Education Committee. Resistant hypertension: diagnosis, evaluation, and treatment: a scientific statement from the American Heart Association Professional Education Committee of the Council for High Blood Pressure Research. Circulation 2008; 117: e510-e526.

15 Logan AG, Perlikowski SM, Mente A, Tisler A, Tkacova R, Niroumand M, Leung RS, Bradley TD. High prevalence of unrecognized sleep apnoea in drug-resistant hypertension. J Hypertens 2001; 19: 2271-2277.
16 Grote L, Hedner J, Peter JH. Sleep-related breathing disorder is an independent risk factor for uncontrolled hypertension. J Hypertens 2000; 18: 679-685.

17 Pratt-Ubunama MN, Nishizaka MK, Boedefeld RL, Cofield SS, Harding SM, Calhoun DA. Plasma aldosterone is related to severity of obstructive sleep apnea in subjects with resistant hypertension. Chest 2007; 131: 453-459.

18 Pickering TG, Miller NH, Ogedegbe G, Krakoff LR, Artinian NT, Goff D, American Heart Association; American Society of Hypertension; Preventive Cardiovascular Nurses Association. Call to action on use and reimbursement for home blood pressure monitoring: a joint scientific statement from the American Heart Association, American Society Of Hypertension, and Preventive Cardiovascular Nurses Association. Hypertension 2008; 52: 10-29.

19 Pickering TG, Eguchi K, Kario K. Masked hypertension: a review. Hypertens Res 2007; 30: $479-488$.

20 Kario K. Time for focus on morning hypertension. Pitfall of current antihypertensive medication. Am J Hypertension 2005; 18: 149-151.

21 Kario K, Ishikawa J, Pickering TG, Hoshide S, Eguchi K, Morinari M, Hoshide Y, Kuroda T, Shimada K. Morning hypertension: the strongest independent risk factor for stroke in elderly hypertensive penitents. Hypertens Res 2006; 29: 581-587.

22 Matsui Y, Eguchi K, Shibasaki S, Shimizu M, Ishikawa J, Shimada K, Kario K. Association between the morning-evening difference in home blood pressure and cardiac damage in untreated hypertensive patients. J Hypertens 2009; 27 (in press).

23 Kario K, Matsuo T, Kobayashi H, Imiya M, Matsuo M, Shimada K. Nocturnal fall of blood pressure and silent cerebrovascular damage in elderly hypertensive patients. Advanced silent cerebrovascular damage in extreme dippers. Hypertension 1996; 27: $130-135$.

24 Kario K, Pickering TG, Matsuo T, Hoshide S, Schwartz JE, Shimada K. Stroke prognosis and abnormal nocturnal blood pressure falls in older Japanese hypertensives. Hypertension 2001; 38: 852-857.

25 Ohkubo T, Hozawa A, Yamaguchi J, Kikuya M, Ohmori K, Michimata M, Matsubara M, Hashimoto J, Hoshi H, Araki T, Tsuji I, Satoh H, Hisamichi S, Imai Y. Prognostic significance of the nocturnal decline in blood pressure in individuals with and without high 24-h blood pressure: the Ohasama study. J Hypertens 2002; 20: 2183-2189.

26 Hoshide S, Kario K, Hoshide Y, Umeda Y, Hashimoto T, Kunii O, Ojima T, Shimada K. Associations between nondipping of nocturnal blood pressure decrease and cardiovascular target organ damage in strictly selected community-dwelling normotensives. Am J Hypertens 2003; 16: 434-438.

27 Kario K, Shimada K, Pickering TG. Abnormal nocturnal blood pressure falls in elderly hypertension: clinical significance and determinants. J Cardiovasc Pharmacol 2003; 41(Suppl 1): S61-S66.

28 Boggia J, Li Y, Thijs L, Hansen TW, Kikuya M, Björklund-Bodegård K, Richart T, Ohkubo T, Kuznetsova T, Torp-Pedersen C, Lind L, Ibsen H, Imai Y, Wang J, Sandoya E, O'Brien $E$, Staessen JA, International Database on Ambulatory blood pressure monitoring in relation to Cardiovascular Outcomes (IDACO) investigators. Prognostic accuracy of day versus night ambulatory blood pressure: a cohort study. Lancet 2007; 370: 1219-1229.

29 Nagai M, Hoshide S, Ishikawa J, Shimada K, Kario K. Ambulatory blood pressure as an independent determinant of brain atrophy and cognitive function in elderly hypertension. J Hypertens 2008; 26: 1636-1641.

30 Kario K. Clinician's Manual on Early Morning Risk Management in Hypertension. Science Press: London, 2004, pp 1-68.

31 Shirasaki O, Yamashita S, Kawara S, Tagami K, Ishikawa J, Shimada K, Kario K. A new technique for detecting sleep apnea-related 'midnight' surge of blood pressure. Hypertens Res 2006; 29: 695-702.

32 Amin R, Somers VK, McConnell K, Willging P, Sherman M, McPhail G, Morgenthal A, Fenchel M, Bean J, Kimball T, Daniels S. Activity-adjusted 24-h ambulatory blood pressure and cardiac remodeling in children with sleep disordered breathing. Hypertension 2008; 51: 84-91. 